\title{
A survey of long-term terrestrial ecology studies in Australia
}

\author{
K. N. YOUNGENTOB, ${ }^{1,2 \star ~ G . ~ E . ~ L I K E N S, ~}{ }^{1,6}$ J. E. WILLIAMS ${ }^{5}$ AND \\ D. B. LINDENMAYER ${ }^{1,3,4}$ \\ ${ }^{1}$ The Fenner School of Environment and Society, The Australian National University, Canberra, ACT \\ 0200, Australia (Email: kara.youngentob@anu.edu.au), ${ }^{2}$ Commonwealth Scientific and Industrial \\ Research Organisation, Division of Marine and Atmospheric Research, ${ }^{3}$ Terrestrial Ecosystem Research \\ Network, ${ }^{4}$ National Environmental Research Program, The Australian National University, Canberra, \\ Australia Capital Territory, ${ }^{5}$ Tasmanian Institute of Agricultural Research, University of Tasmania, \\ Burnie, Tasmania, Australia; and ${ }^{6}$ Cary Institute of Ecosystem Studies, Millbrook, New York, USA
}

\begin{abstract}
Long-term ecological studies (LTES) are critical for understanding and managing landscapes. To identify important research gaps, facilitate collaborations and communicate results, several countries have established long-term ecological research networks. A few initiatives to create such a network in Australia have been undertaken, but relatively few published data exist on the current state of LTES in Australia. In this paper, we present the results of an online survey of terrestrial LTES projects sent to academic, government and nongovernmental organization-based researchers across Australia. We asked questions pertaining to the focus, scope, support and outcomes of LTES spanning 7 years or longer. Based on the information reported from 85 Australian LTES, we: (i) identify the biomes, processes and species that are under-represented in the current body of research; (ii) discuss important contributing factors to the successful development and survival of these projects; and (iii) make recommendations to help increase the productivity and influence of LTES across research, management and policy sectors.
\end{abstract}

Key words: Australia, conservation, database, ecological research, landscape management, LTER, monitoring, survey.

\section{INTRODUCTION}

Throughout much of its relatively short history, most ecological research has been funded for short periods of time and on small spatial scales (Callahan 1984; Gosz 1996). However, as paradigms have shifted from a steady-state, equilibrium-based perception of the environment to one of continual flux, heterogeneity and inherent stochastic disturbance, the importance of long-term ecology studies (LTES) has become more apparent (Connell \& Sousa 1983; Likens 1989; Gosz 1996; Pickett et al. 1997; Willis \& Birks 2006). The ability to manage our rapidly changing environment and limited natural resources will depend largely on support for LTES and collaboration among researchers to maximize the benefits of these initiatives (Landres et al. 1999; Lindenmayer \& Likens 2010).

We present the results of a survey of long-term terrestrial ecology studies in Australia. This information is intended to help scientists and policy makers identify current knowledge gaps and foster discussion about

${ }^{\star}$ Corresponding author.

Accepted for publication May 2012.

(C) 2012 The Authors

Austral Ecology (C) 2012 Ecological Society of Australia the management, contributions and future direction of LTES. Using the results of this survey as a platform, we will create a publically available online database of LTES in Australia, which will be accessible through the Ecological Society of Australia (ESA) and Terrestrial Ecosystem Research Network (TERN) websites. We hope that this database will inform ecologists and landscape managers about ongoing research, encourage productive collaboration among researchers and facilitate more standardized data collection and analysis techniques to broaden the scope and contribution of otherwise disparate research initiatives.

Effective planning for future LTES requires an understanding of the current state of LTES, clear questions around which future data are collected, and an accessible platform for promoting collaboration and continuity to maximize outcomes and attract future funding (Lindenmayer \& Likens 2010). Based on similar ideology, several countries have initiated, or are in the process of initiating, LTES networks (Hobbie 2003; Collins 2010; Tripathi 2010). The long-term ecological research (LTER) concept began in the USA in 1980 (Callahan 1984; Gosz 1996) and led to similar efforts around the world. In recognition 
of the need to expand LTER to a global scale, the US LTER network spawned an international LTER initiative in 1993 (ILTER; http://www.ilternet.edu/).

Australia is currently represented in the ILTER network by four projects; Warra (Tasmania), Forestcheck (Western Australia), Karawatha Forest Park (Queensland) and Lake Broadwater Conservation Park (Queensland). Three of these sites are dominated by forest biomes. Other attempts to document LTER in Australia include a Department of Agriculture, Fisheries and Forestry website on Australia's LTER forest sites, comprised of five studies (http:// www.daff.gov.au/brs/forest-veg/research-sites) and an ESA survey and database (Williams et al. 2001). The ESA survey included 145 studies across a range of biomes that were intended to span 10 years or longer, but were not necessarily long-term at the time of the survey in 2000 (Hahs 2001). The ESA data were analysed as part of the national State of the Environment reporting process in 2001 (Williams et al. 2001). In addition to its survey efforts, the ESA began compiling a database of LTER in 1986, which has been updated twice since its inception, once in 1995 and again in 2000 (Hahs 2001).

Our study builds upon the earlier LTER survey and documentation initiatives by the ESA (Hahs 2001; Williams et al. 2001). Unlike the earlier ESA survey, we included only studies that had already spanned 7 years or longer at the time that this survey was completed. We use the term LTES in this study rather than LTER because the information we collected includes studies that are research based or have an experimental component, as well as monitoring-based studies that do not involve experimental aspects. The LTES terminology also avoids confusion with defined LTER and ILTER programmes. This project is intended to help create a more complete network of LTES in Australia. This information should assist Australian researchers in contributing to national and international LTES initiatives.

\section{METHODS}

\section{Participant selection}

We identified potential respondents by searching Australian university, non-governmental organization (NGO), and state and federal government department websites. We collected publically available email addresses for all professors, associate professors and visiting fellows in university departments or research groups in Australia with a focus in biology, botany, zoology, ecology, environmental science, environmental management, forestry, agriculture and sustainability. We also obtained email contact addresses from the public websites of Australian-based national and international NGOs and Australian state and federal government depart- ments with environment, conservation, forestry, agriculture, fisheries, wildlife, parks and climate change related interests. We attempted to obtain every email address consistent with the above criteria. However, there was considerable variability in the accessibility of university, NGO, and government department website contact information, and the willingness of organizations to forward our request for participation when direct email addresses were not available. For these reasons, it is likely that we were not able to contact every relevant department or individual. We also sent emails to the mailing lists of the ESA and the former Applied Environmental Decision Analysis division of the Commonwealth Environment Research Facilities. In our initial contact email, we requested that potential respondents forward our questionnaire to other researchers who might be able to participate in this study.

Initially, we canvassed both terrestrial and marine LTES. However, the survey instrument was strongly oriented towards terrestrial ecology research and inland aquatic ecosystems (i.e. wetlands, rivers, floodplains and lakes). This limited our ability to assess the state of marine LTES in Australia and may have deterred some marine ecologists from responding. In addition, the small number of marine research-based responses suggested that the sampling of marine ecologists was not adequate. Therefore, we decided to remove the marine research-based component from the analysis. However, we are working in collaboration with marine research scientists to more successfully incorporate these fields into the online database, which will be available in late 2012 .

\section{Survey instrument and analyses}

We conducted an email and web-based survey of the potential respondents indentified from the Australian university, NGO and government department websites. We contacted potential respondents through an initial email invitation to participate (the wording for the initial email is given in Appendix S1, available online). This email included a link to the online cover letter and survey questionnaire in a PDF format (Appendix S2, available online). We sent a total of 994 emails to potential respondents or list-serve email addresses in Australia. The cover letter provided a brief explanation of the study objectives, directions for completing the questionnaire, and information regarding confidentiality and participant rights. We requested that individuals complete our questionnaire if they had been involved in a study or were currently involved in a study that spanned 7 years or longer. It was not necessary for the study to be ongoing.

Using the online survey questionnaire, we asked respondents 31 questions designed to investigate the focus, scope, support and outcomes of their LTES. Survey question types included Likert scale (Babbie 2005), yes-no, fill-in-theblank, open-ended, questions that asked the respondent to choose the best response from a list of possible answers, and questions that required the respondent to rank a list of responses. We tested question answerability on a subset of the total survey respondents $(n=33)$ whom we contacted in September and October 2008. We contacted the remaining potential respondents by email between May and July 2010 .

(C) 2012 The Authors

Austral Ecology (C) 2012 Ecological Society of Australia 
The number of responses for each question varied because participants were able to leave blank any questions that they did not want to answer. Partially answered questions were included in our analysis where the data allowed. Several questions also allowed respondents to select more than one answer and this resulted in the total frequency of responses exceeding $100 \%$ in some instances. We present the results from the quantitative survey questions using basic, descriptive statistics, and we include the number of surveys $(n)$ in which each question was answered. In a few instances, we used Student's $t$-tests to compare response rates (log means) between groups and generalized linear models to investigate the influence of potential explanatory variables on response rates. Some open-ended questions were not analysed for this paper due to the qualitative nature of those responses (Appendix S2, question numbers 1, 8b, 8c, 20, 22b, 24, 25, 29-31, available online). However, all question responses will be included in the online database unless otherwise requested by the respondents.

\section{RESULTS}

\section{LTES objectives}

We received 87 survey questionnaires from respondents involved in long-term terrestrial ecology studies. Two respondents reported studies that did not meet our 7 year threshold ( 3 years and 5 years respectively) and their responses were not included in the analysis. A full list of LTES names and locations can be found in Appendix S3 (available online). The oldest LTES began in 1926 and the most recent was initiated in 2004. One respondent indicated that their study began in the 1900s and another in the 1930s, but no specific year was given. Based on the studies that reported a specific starting year $(n=83)$, the average study age was 23.4 years and the median was 21 years. The majority of studies were ongoing (76 of 85 studies).

When asked whether the original objectives were still central to the study on a Likert scale of 1 to 5 (from not at all central to very central), most respondents felt that the original objectives were still central (average 4.4, $n=85$ ). The majority $(80 \%)$ indicated that the original objectives were still central or very central to the study. A minority of respondents indicated that the original objectives were no longer central $(4.7 \%)$ or were somewhat central $(15.3 \%)$ to the study.

The most common landscape-type studied by the LTES survey respondents was eucalypt open woodlands $(29.8 \%$ of projects, Fig. 1). Low closed forests were the least common (2.4\% of projects). Most studies involved more than one landscape type $(65.5 \%)$. We found that vascular plants were the most common taxa investigated in LTES (60\% of projects, Fig. 2). The least represented group were bacteria $(4.7 \%$ of projects). Among vertebrates, birds and

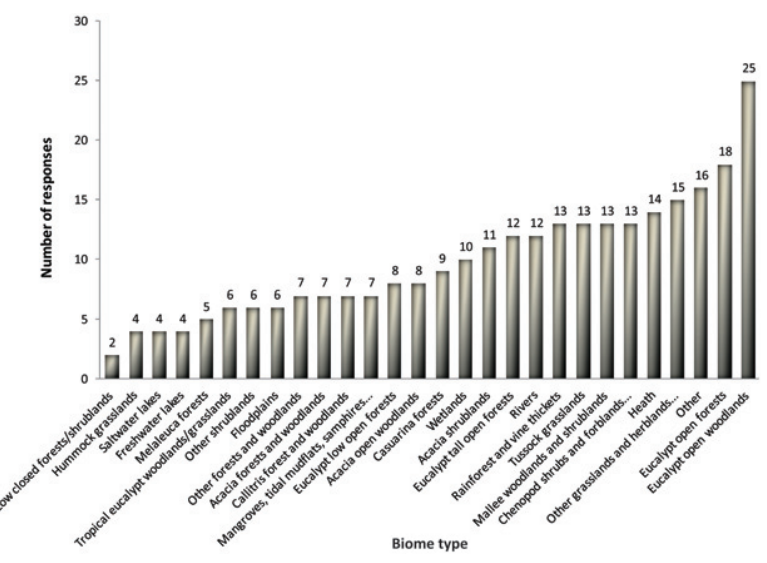

Fig. 1. The vegetation and biome-types included in longterm studies (the total number of surveys in which this question was answered $(n)=85)$. In instances where the type names are abbreviated, the full text is available in Appendix S2 (available online).

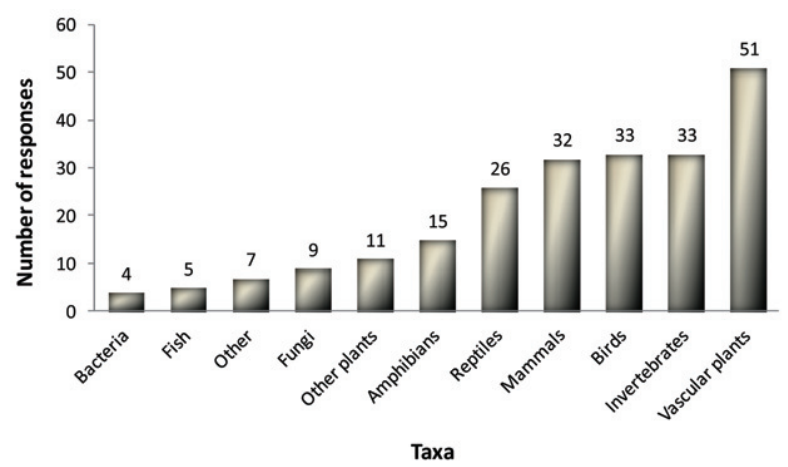

Fig. 2. The type of taxa being investigated in long-term studies $(n=85)$.

mammals were the most frequently studied taxa in LTES (38.8\% and $37.6 \%$ respectively). Amphibians and fish were the least studied vertebrates $(17.6 \%$ and $5.9 \%)$. The majority of projects $(61.2 \%)$ involved more than one taxon.

We found that biomass accumulation was the most common type of ecosystem process studied $(60.4 \%$ of projects, Fig. 3). Respondents listed population dynamics, community composition, species interactions and physiology most frequently in the 'other' category. Habitat degradation was the most common threatening processes investigated by the LTES respondents (63.4\% of projects, Fig. 4 ). We found that disease transmission and impact was the least studied threatening processes $(6.1 \%$ of projects).

The majority of respondents indicated that the original design of the LTES involved an experimental component ( $57.3 \%$ yes compared to $42.7 \%$ no, $n=82$ ). We found that most LTES had run continuously since the beginning of the study ( $72.9 \%$ yes compared to $27.1 \%$ no, $n=85)$. 


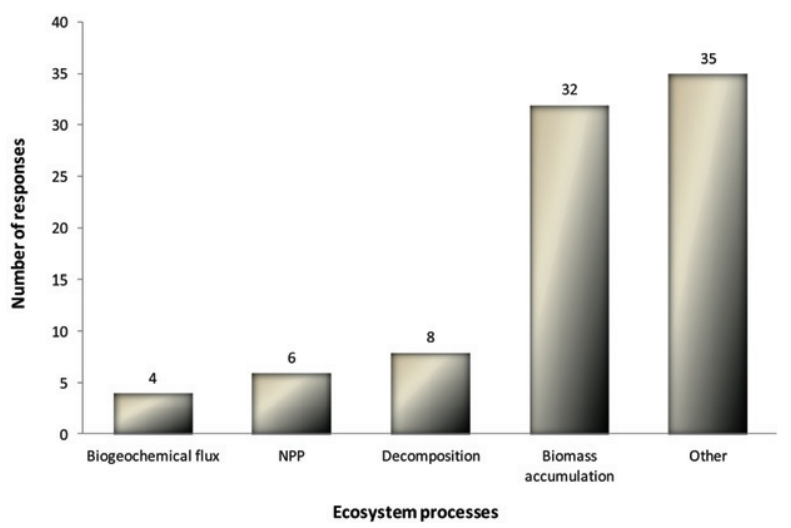

Fig. 3. Ecosystem processes examined in the long-term studies $(n=53)$. NPP is net primary productivity.

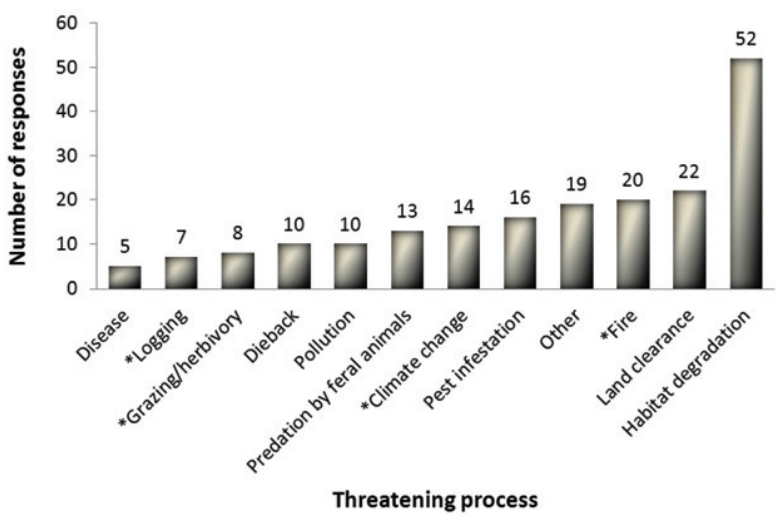

Fig. 4. The type of threatening process investigated in long-term studies $(n=82)$. ${ }^{\star}$ These categories were derived from responses mentioned multiple times in the 'other' category.

\section{LTES contributors}

Individuals were most often in charge of an LTES $(77.6 \%)$, followed by an institution or agency $(42.4 \%)$, other $(14.1 \%)$ and a committee $(11.8 \%)$. When an individual was in charge $(n=66)$, an average of 2.6 people had served in this position since the beginning of the study. The LTES employed an average of 0.9 full-time workers and 1.8 part-time workers per study. The average number of unpaid full-time and part-time workers per LTES study was 0.2 and 10.8 respectively.

Respondents ranked staff scientists as the most important contributors to LTES projects, followed by technicians and graduate students (Fig. 5). Administrative personnel were ranked as the least valuable contributors. We found that volunteers were the most frequently indicated response within the 'other' category $(46.2 \%$ of 'other' responses, $n=26)$. Notably, the average ranking for 'volunteers,' when they were mentioned, was 4.1 , placing them near graduate students in the importance of their contribution.

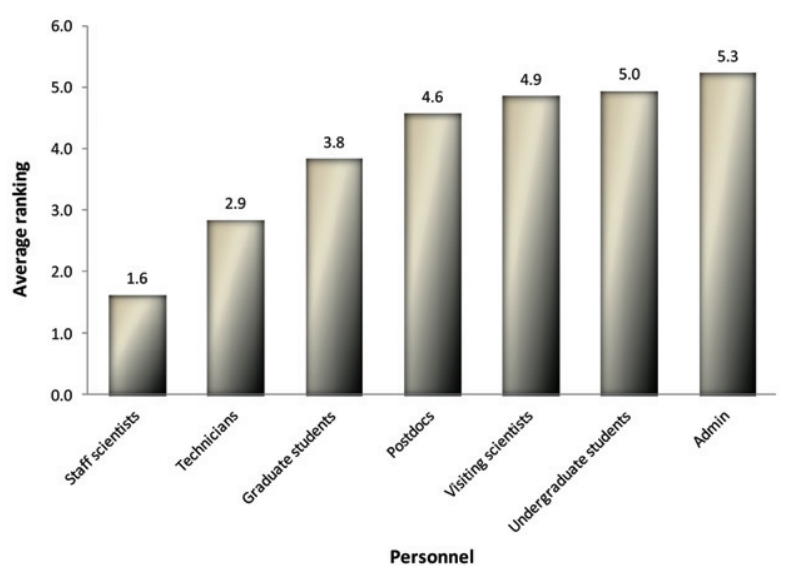

Fig. 5. Average ranking of personnel involved in long-term studies in regards to their contribution $(n=82)$. Ranking was assigned from 1 to 7 , with 1 being the most important and 7 the least. The average rank for 'other' was determined separately and the value is provided in the text.

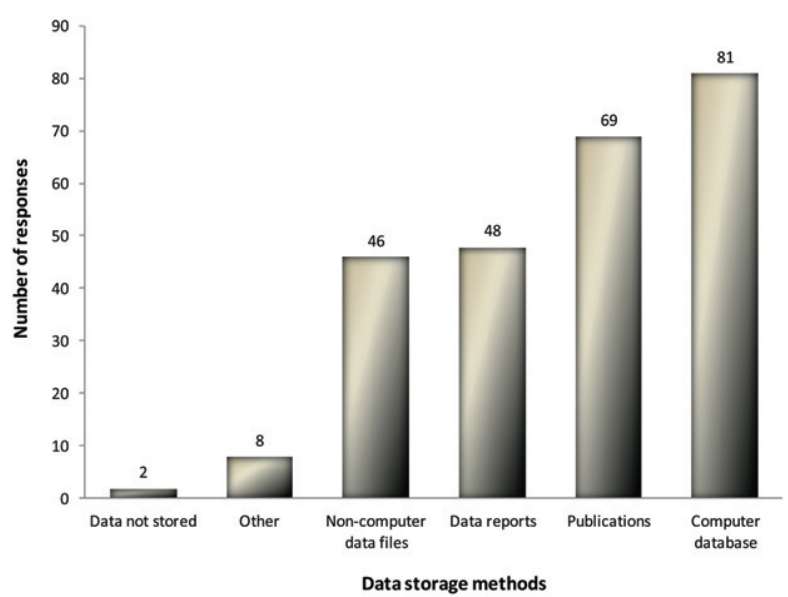

Fig. 6. Data archive and storage methods from long-term studies $(n=82)$.

\section{LTES data storage and availability}

Raw data from the LTES were most often archived in computer databases and publications $(95.3 \%$ and $81.2 \%$ of responses respectively, Fig. 6 ). A small proportion of respondents reported that they did not store their data in any manner $(2.4 \%)$. We found that most respondents archived their study site locations $(86.9 \%$ yes compared to $13.1 \%$ no, $n=84$ ) and their methods $(90.5 \%$ yes and $9.5 \%$ no, $n=84)$. A majority of respondents also indicated that their data were stored in more than one geographic location $(67.9 \%$ yes and $32.1 \%$ no, $n=84)$. Most respondents made their data available to scientific collaborators $(80 \%$, Fig. 7$)$. The smallest proportion of respondents indicated that they made their data available to the general public or no one else ( $8.2 \%$ and $10.6 \%$ respectively).

(C) 2012 The Authors

Austral Ecology (C) 2012 Ecological Society of Australia 


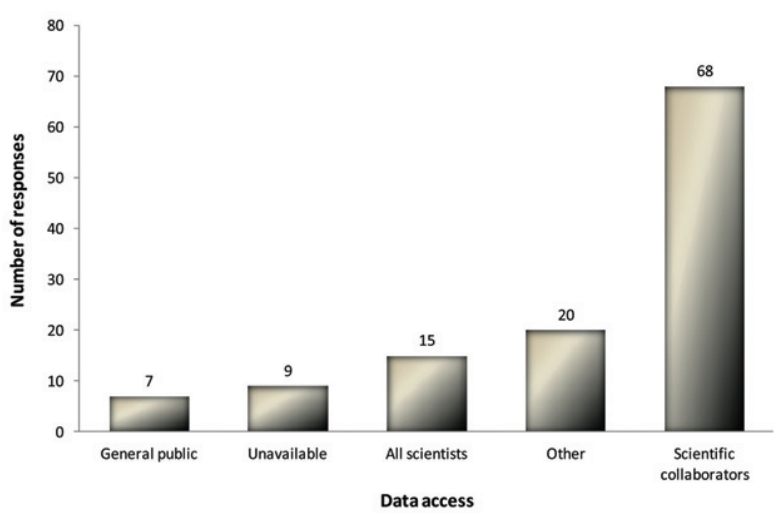

Fig. 7. Data availability from long-term studies to particular user groups $(n=82)$.

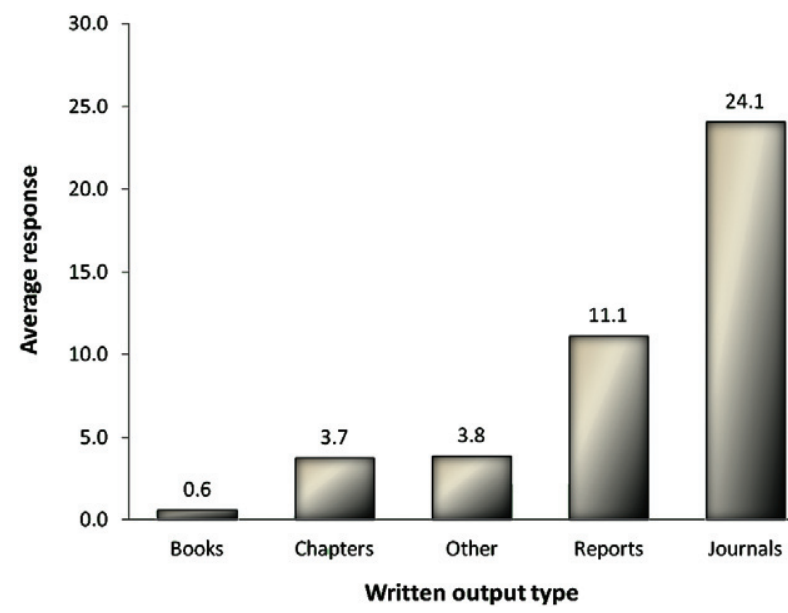

Fig. 8. The average written output per long-term ecology study $(n=76)$.

\section{LTES written outputs}

The results from LTES were most often published in peer-reviewed journals (average of 24.1 per study), followed by technical reports (11.1 per study, Fig. 8). Books represented the least common written outlet for LTES results ( 0.6 per study). The number of publications per LTES varied greatly among studies and ranged from a minimum per LTES of 0 across all publication categories to a maximum of 200 for journals (median 7), 120 for reports (median 4), 58 for other publications (median 0), 31 for book chapters (median 1) and 6 for books (median 0).

Respondents were almost as likely to report that publication rates decreased over time $(31.7 \%)$ as they were to report that publication rates increased over time $(35.4 \%)$, which resulted in an average of 3 on a 5 -point Likert scale (3 indicating no change, $n=82$ ). There was no significant relationship between study age and total number of publications $(P=0.20)$.

(C) 2012 The Authors

Austral Ecology (C) 2012 Ecological Society of Australia
Survey respondents who were affiliated with a university (based on their contact email address) published significantly more peer-reviewed journal articles (backtransformed values (btv), government $=3.4$, university 15.7, $\mathrm{t}_{54}=-3.37, P=0.001$ ), other publications (btv government $=1.2$, university $0.4, \mathrm{t}_{54}=2.12, P=0.04$ ), and total publications (btv government $=10.3$, university $\left.35.1, \mathrm{t}_{54}=-3.24, P=0.002\right)$ than government affiliated respondents. There was no significant difference in publication rate between these two groups for reports (btv government $=3.0$, university 5.2, $\left.\mathrm{t}_{54}=-1.15, P=0.26\right)$, books (btv government $=0.2$, university $0.5, \mathrm{t}_{54}=-1.76, P=0.08$ ) or book chapters (btv government $=1.3$, university $2.7, \mathrm{t}_{54}=-1.64$, $P=0.11$ ).

An average of 3.6 undergraduate theses, 0.8 Master theses, and 2.4 $\mathrm{PhD}$ theses resulted from each LTES $(n=65)$. However, this varied widely across LTES ( $\mathrm{min} / \mathrm{max}$ range $0-22 \mathrm{PhD}, 0-9 \mathrm{MSc}, 0-21$ BSc). Survey respondents who were affiliated with a university reported significantly more $\mathrm{PhD}$ theses (btv government $=0.5$, university $1.9, \mathrm{t}_{54}=-3.10, P=$ $0.003)$ and undergraduate theses $(\mathrm{btv}$ government $=$ 0.5 , university $\left.2.2, \mathrm{t}_{54}=-3.32, P=0.002\right)$ than government affiliated respondents. There was no significant difference between these two groups for Master theses (btv government $=0.3$, university $0.5, \mathrm{t}_{54}=-0.88$, $P=0.38)$. Notably, a relatively small number of Master theses was reported by survey respondents compared to the other theses categories $(n=178 \mathrm{PhD}, 49 \mathrm{MSc}, 321$ undergraduate theses).

\section{LTES funding}

We found that competitive grants comprised $38.9 \%$ of LTES funding on average $(n=81)$ and noncompetitive grants comprised $25.6 \%$. These grants were most frequently sourced from the government, followed by other public and then private sources. Endowments comprised $3.9 \%$ of funding for LTES. In this case, private sources were the most frequent contributor to endowments. Government and other public sources were indicated only one time each in the endowment category. Other sources comprised $27 \%$ of funding for LTES on average. Government was the most frequently selected source for this funding, followed by private and then other public sources. The majority of LTES operated on 5000 to 50000 Australian dollars per year on average $(40.8 \%$ of projects, Fig. 9). The smallest proportion of LTES (6.6\%) operated on more than 250000 Australian dollars per year.

\section{DISCUSSION}

This study builds on the earlier initiatives by the ESA to collect information on LTES in Australia. Although 


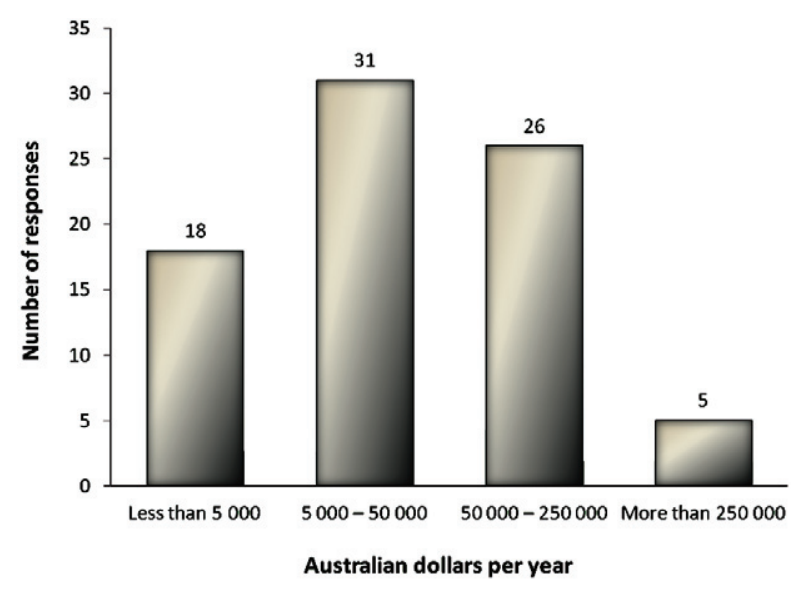

Fig. 9. Average cost of long-term projects per year, averaged over the course of the study $(n=76)$.

Australia is recognized as having an LTER network in development (Gosz 1996) and is represented in the ILTER network by a handful of studies, there is relatively little published information regarding the current state of long-term ecological work in Australia (for exceptions see Hahs 2001 and Williams et al. 2001). Here we discuss the results of a recent survey of researchers across Australia, who are involved in, or have been involved in, a long-term terrestrial ecology study. By publishing the results of this survey, we aim to inform a large audience of ecologists and environmental managers about the state of LTES in Australia, promote collaborations and integrations among researchers and their long-term studies, facilitate the development of future LTER projects, and identify some important strengths and weaknesses in the current body of Australian LTES.

\section{LTES objectives}

Surveys of ecological research often report biases in data collection towards landscapes and taxa that are relatively accessible and easy to survey (Fazey et al. 2005; Felton et al. 2009). Not surprisingly then, the most frequently investigated taxa in the Australian LTES survey were vascular plants, invertebrates and birds. The least studied taxa included bacteria and among vertebrates, fish and amphibians. A similar bias for vascular plants over other taxa also was reported by the ESA survey in 2000 (Hahs 2001; Williams et al. 2001). However, unlike the earlier ESA survey, we found that most studies in the current survey included more than one biome-type and taxa.

Individual species are often poor indicators of entire systems (Lindenmayer \& Fischer 2003; Lindenmayer et al. 2007). LTES that investigate multiple species and biome-types may increase their effectiveness in answering questions about ecosystem processes and functioning (Lindenmayer \& Likens 2011).

Bacteria were the least studied group in the LTES despite their prevalence and importance in ecological processes such as decomposition, disease transmission and biogeochemical fluxes (King \& Weber 2007). Their lack of representation in LTES is a critical shortcoming (Zavarzin 2008; Donoghue \& Antcliffe 2010; Krammer et al. 2011). Among larger organisms, our finding that fish and amphibians were underrepresented by LTES compared to birds and mammals is consistent with other reviews of ecological studies (e.g. Bonnet et al. 2002; Fazey et al. 2005; Felton et al. 2009). An important caveat is that we did not include marine LTES in this analysis. The number of reported studies involving fish is based on inland aquatic environments and this is not representative of studies involving these animals across all Australian LTES. However, the low numbers of amphibianoriented studies is concerning, and future research should invest more attention to these diverse taxa, which also can be highly sensitive to environmental changes (e.g. Pounds et al. 2006; Strayer \& Dudgeon 2010).

Another finding in common with the 2000 ESA survey was that temperate eucalypt woodlands were the most frequently studied vegetation/biome-type in Australian LTES. Temperate eucalypt woodlands overlap with some of the most highly modified landscapes for agricultural production in southern and eastern Australia (e.g. the Australian wheat-sheep belt, Lindenmayer et al. 2010). For this reason, they are both critically threatened ecosystems (Hoekstra et al. 2005) and relatively accessible to researchers. Although we agree that these landscapes should be research priorities, attention also should be given to less researched biomes in LTES. For example, the recent floods across much of eastern Australia present an ideal opportunity to establish LTER in replenished saltwater and freshwater lake ecosystems. These may be dry for decades between flood events but represent important pulses in productivity and populations of many species (Kingsford et al. 1999). Our understanding of these ecosystems before, during and after major flood events is very limited (Lake et al. 2006).

A majority of LTES involved an experimental component. However, almost half (43\%) did not. The importance of establishing research questions upfront and incorporating rigorous statistical design to address those questions in an experimental framework has been the focus of several recent papers (e.g. Lindenmayer \& Likens 2009, 2010). Passive monitoring that lacks specific questions and a statistically sound study design is limited in its ability to make predictions about future conditions due to a failure to investigate the processes underpinning observed response patterns (Field et al. 2007; Lindenmayer \& Likens 2010). 
For these reasons, we urge researchers to carefully consider their research questions at the outset, develop conceptual models, and test hypotheses resulting from those models using appropriate study design, data collection and data analysis techniques.

\section{LTES contributors}

Long-term ecology studies benefit from strong, dedicated leadership (Strayer et al. 1986; Lovett et al. 2007; Lindenmayer \& Likens 2010) and we found that the vast majority of LTES in our survey were run by a single individual. In most of the studies, only one or two people had served in this leadership role for the duration of the LTES, and many respondents listed a dedicated project leader as the single most important attribute to ensuring the continued productivity of LTES. Although this LTES 'champion' is undeniably critical for the success of LTES (Lindenmayer \& Likens 2010), we also found that many other people played an important role in these studies. In particular, staff scientists (presumably including the principal investigator), technicians and graduate students ranked highly in their contributions. Although volunteer contribution varied substantially among studies, LTES that utilized volunteers ranked the contributions of volunteers highly. Notably, relatively few paid personnel were involved in the LTES surveyed, and over four times as many unpaid staff participated in the projects as paid staff.

\section{LTES data storage and availability}

Data obtained during LTES may be used in ways that are not anticipated at the outset of the project and could continue to have value for many decades after they are collected. For these reasons, careful archiving of site information, methodology, collected data and analyses is essential. Data should always be stored in more than one geographical location and a majority of respondents indicated that they already do this. In addition, given the rapid turnover in computer software and technology, data should be stored in such a way that it will be accessible in the future. The same holds true for methods and site descriptions.

There is considerable debate regarding intellectual property and who should have access to LTES data (Lindenmayer \& Likens 2010; Likens \& Lindenmayer 2011). The majority of respondents indicated that their data are available to scientific collaborators but few allowed data to be available to anyone per se. Whatever the policy of individual LTES, the availability, dissemination and attribution of LTES data should be clearly established and agreed upon by team members to protect intellectual property rights and facilitate productive collaborations (Likens 2001; Lovett et al. 2007).

\section{LTES written outputs}

Important gauges of scientific productivity are written outputs in the form of peer-reviewed scientific papers, reports, books and book chapters (Lindenmayer \& Likens 2010). Communicating results is critical to any successful LTES and for attracting continued funding. Universities, in particularly, emphasize the importance of publishing results in peer-reviewed academic journals; whereas these outputs are not as highly valued by government agencies (Gibbons et al. 2008). Not surprisingly, we found that LTES written outputs in the form of peer-reviewed scientific papers and all written outputs were highest among respondents who were affiliated with an academic institution. Similarly, PhD and undergraduate theses numbers resulting from LTES also were higher among university affiliated respondents.

We found considerable variability in all forms of written productivity from LTES in Australia, with the most productive LTES generating 50 times more written output than the least productive ones. A common criticism of LTES is that they are wasteful, unproductive, results are poorly communicated and not policy oriented (Lovett et al. 2007; Lindenmayer \& Likens 2010). However, this need not be the situation. Lindenmayer and Likens (2010) make the case that well-designed, question-driven LTES, combined with the frequent examination of data, imbedded shorterterm research projects and cross-sectional studies and timely, policy-targeted reports can improve the overall written output and influence of LTES. Our results suggest that government-run LTES that develop collaborative links with academics may improve their productivity, and such collaborations also may help insure that academic research targets policy needs (Gibbons et al. 2008).

\section{LTES funding}

Access to funding is cited as a common hurdle to establishing and maintaining LTES (Lovett et al. 2007; Lindenmayer \& Likens 2010). The relatively small amount of money and few paid employees required to maintain LTES suggests that welldesigned, well-managed, well-performing LTES can be very cost-effective. We found that $64.5 \%$ of LTES require $\$ 50000$ Australian dollars or less to run on an annual basis. The results of this study emphasize the importance of government and other public funding for LTES. Endowments and other private sources of 
funding can make important contributions to LTES as well, and these should be actively pursued by LTES researchers (Lindenmayer \& Likens 2010).

\section{CONCLUSIONS}

Long-term ecology studies are essential for understanding Earth's complex and dynamic ecological systems and the ability to manage them (Gosz 1996; Lindenmayer 1999; Lovett et al. 2007). Given the temporal variability inherent in many natural environments, short-term ecological research can result in false conclusions about ecological systems and their responses to environmental change (Likens 1989). In recognition of the importance of LTES to our understanding of environmental change and management, numerous countries have established LTER networks. This paper represents a continuation of ongoing efforts by the ESA to collect information on LTES in Australia.

It is our intention to use the data presented in this paper to create an online database of Australian LTES. This database will be available through the ESA and TERN websites, and will include information on project locations, objectives and published outputs. We recognize that there are still sites that have not been captured in this survey or in the earlier ESA surveys, all of which were based on voluntary responses. We therefore welcome input from researchers whose LTES are not as yet included in the forthcoming database that will be developed from the work reported here. If you would like information on an LTES in which you are involved to be added to this database, please contact the corresponding author. It is our intention for this survey and the database to help improve LTES outcomes by facilitating communication and collaborations among researchers, government agencies and other landscape managers.

\section{ACKNOWLEDGEMENTS}

The authors thank The Fenner School of Environment and Society at The Australian National University, the Department of Limnology, University of Uppsala, Sweden and the Australian Government Commonwealth Environment Research Facilities programme, for their generous support. This survey was approved by The Australian National University Office of Research Integrity (Ethics Approval 2010/094). We acknowledge Rachel Muntz for her contributions to this project and Dr Jeff Woods for his assistance with statistical analyses. We also thank Dr Elliot Fraval, Arantxa Cabello and Samantha Vertucci for data man- agement, and the survey respondents for their invaluable contributions to this study and LTER.

\section{REFERENCES}

Babbie E. (2005) The Basics of Social Research. Wadsworth Publishing Company, Belmont.

Bonnet X., Shine R. \& Lourdais O. (2002) Taxonomic chauvinism. Trends Ecol. Evol. 17, 1-3.

Callahan J. T. (1984) Long-term ecological research. BioScience 34, 363-67.

Collins S. L. (2010) Ecosystem response to climate change: short term experiments and long-term ecological research. The 95 $5^{\text {th }}$ ESA Annual Meeting, Pittsburgh, Pennsylvania.

Connell J. H. \& Sousa W. P. (1983) On the evidence needed to judge ecological stability or persistence. Am. Nat. 121, 789824.

Donoghue P. C. J. \& Antcliffe J. B. (2010) Early life: origins of multicellularity. Nature 466, 41-2.

Fazey I., Fischer J. \& Lindenmayer D. B. (2005) What do conservation biologists publish? Biol. Conserv. 124, 63-73.

Felton A., Fischer J., Lindenmayer D. B. et al. (2009) Climate change, conservation and management: an assessment of the peer-reviewed scientific journal literature. Biodivers. Conserv. 18, 2243-53.

Field S. A., O'Connor P. J., Tyre A. J. \& Possingham H. P. (2007) Making monitoring meaningful. Austral Ecol. 32, 485-91.

Gibbons P., Zammit C., Youngentob K. et al. (2008) Some practical suggestions for improving engagement between researchers and policy-makers in natural resource management. Ecol. Manage. Restor. 9, 182-86.

Gosz J. R. (1996) International long-term ecological research: priorities and opportunities. Trends Ecol. Evol. 11, 444.

Hahs A. K. (2001) Long-term ecological research in Australia. Bull. Ecol. Soc. Aust. 31, 11-4.

Hobbie J. E. (2003) The US long term ecological research program. BioScience 53, 21-32.

Hoekstra J. M., Boucher T. M., Ricketts T. H. \& Roberts C. (2005) Confronting a biome crisis: global disparities of habitat loss and protection. Ecol. Lett. 8, 23-9.

King G. M. \& Weber C. F. (2007) Distribution, diversity and ecology of aerobic CO-oxidizing bacteria. Nat. Rev. Microbiol. 5, 107-18.

Kingsford R. T., Curtin A. L. \& Porter J. L. (1999) Water flows on Cooper Creek determine 'boom' and 'bust' periods for waterbirds. Biol. Conserv. 88, 231-48.

Krammer E.-M., Bernad S., Ullmann G. M., Hickman A. \& Sebban P. (2011) Corrigendum to: chemical evidence for the dawn of life on earth. Aust. F. Chem. 64, 228.

Lake S., Bond N. \& Reich P. (2006) Floods down rivers: from damaging to replenishing forces. Adv. Ecol. Res. 39, 41-62.

Landres P. B., Morgan P. \& Swanson F. J. (1999) Overview of the use of natural variability concepts in managing ecological systems. Ecol. Appl. 9, 1179-88.

Likens G. E. (1989) Concluding remarks. In: Long-Term Studies in Ecology: Approaches and Alternatives (ed. G. E. Likens) pp. 209-10. Springer-Verlag, New York.

Likens G. E. (2001) Ecosystems: energetics and biogeochemistry. In: A New Century of Biology (eds W. J. Kress \& G. Barrett) pp. 53-88. Smithsonian Institution Press, Washington, DC; London.

(C) 2012 The Authors

Austral Ecology (C) 2012 Ecological Society of Australia 
Likens G. E. \& Lindenmayer D. B. (2011) A Strategic Plan for an Australian Long-Term Environmental Monitoring (LTEM) Network. Austral Ecol. 36, 1-8.

Lindenmayer D. B. (1999) Future directions for biodiversity conservation in managed forests: indicator species, impact studies and monitoring programs. For. Ecol. Manag. 115, 277-87.

Lindenmayer D. B., Bennett A. F. \& Hobbs R. (2010) An overview of the ecology, management and conservation of Australia's temperate woodlands. Ecol. Manage. Restor. 11, 201-9.

Lindenmayer D. B., Fischer J., Felton A. et al. (2007) The complementarity of single-species and ecosystem-oriented research in conservation research. Oikos 116, 1220-6.

Lindenmayer D. B. \& Fischer J. F. (2003) The focal species approach: sound science or social hook. Landscape Urban Plan. 62, 149-58.

Lindenmayer D. B. \& Likens G. E. (2009) Adaptive monitoring: a new paradigm for long-term research and monitoring. Trends Ecol. Evol. 24, 482-6.

Lindenmayer D. B. \& Likens G. E. (2010) The science and application of ecological monitoring. Biol. Conserv. 143, 1317-28.

Lindenmayer D. B. \& Likens G. E. (2011) Direct measurement versus surrogate indicator species for evaluating environmental change and biodiversity loss. Ecosystems 14, 47-59.

Lovett G. M., Burns D. A., Driscoll C.T. et al. (2007) Who needs environmental monitoring? Front. Ecol. Environ. 5, 253-60.

Pickett S. T. A., Burch W. R., Dalton S. E. \& Foresman T. W. (1997) Integrated urban ecosystem research. Urban Ecosyst. $1,183-84$.

Pounds J. A., Bustamante M. R., Coloma L. A. et al. (2006) Widespread amphibian extinctions from epidemic disease driven by global warming. Nature 439, 161-7.
Strayer D., Glitzenstein J. S., Jones C. G. et al. (1986) Long-term ecological studies: an illustrated account of their design, operation, and importance to ecology. Occasional Publication of the Institute of Ecosystem Studies 2, Millbrook, NY.

Strayer D. L. \& Dudgeon D. (2010) Freshwater biodiversity conservation: recent progress and future challenges. $\mathcal{F} . N$. Am. Benthol. Soc. 29, 344-58.

Tripathi S. K. (2010) The need for establishing long-term ecological research network in India. Curr. Sci. India 98, 21-2.

Williams J. E., Read C. Norton T., Dovers S., Burgman M., Proctor W. \& Anderson H. (2001) Biodiversity, Australia State of the Environment Report 2001 (Theme report). CSIRO Publishing on behalf of the Department of Environment and Heritage.

Willis K. J. \& Birks H. J. B. (2006) What is natural? The need for a long-term perspective in biodiversity conservation. Science 314, 1261-65.

Zavarzin G. (2008) A planet of bacteria. Her. Russ. Acad. Sci. 78, 144-51.

\section{SUPPORTING INFORMATION}

Additional Supporting Information may be found in the online version of this article:

Appendix S1. The initial contact email sent to potential survey respondents.

Appendix S2. Survey cover letter and Questionnaire. Appendix S3. List of study names and locations.* 